\title{
Development of a Rat Model of Knee Osteoarthritis by a Combination of Monoiodoacetate and Streptozotocin
}

\author{
Desarrollo de un Modelo de Rata de Osteoartritis de Rodilla por \\ una Combinación de Monoiodoacetato y Estreptozotocina \\ El Hassan A. Heidar ${ }^{1,7}$; Bahjat Al-Ani2*; Mohamed A. Haidara ${ }^{2,8^{*}}$; Fareed F. Al Faya ${ }^{3}$; \\ Suliman Al Humayed ${ }^{4}$; Refaat A. Eid ${ }^{5}$ \& Waleed N. Hassan ${ }^{6}$
}

HEIDAR, E. H. A.; AL- ANI, B.; HAIDARA, M. A.; AL FAYA, F. F.; AL HUMAYED, S.; EID, R. A. \& HASSAN, W. N. Development of a rat model of knee osteoarthritis by a combination of monoiodoacetate and streptozotocin. Int. J. Morphol., 35(4):1383-1390, 2017.

SUMMARY: Osteoarthritis (OA) caused by ageing joints or as a secondary complication of diabetes is a common health problem. We sought to develop an animal model of OA induced by a combination of the chondrocyte glycolytic inhibitor mono-iodoacetate (MIA) and streptozotocin (STZ), the agent that induces diabetes mellitus. We then hypothesized that the extent of damages to the knee joint induced by this model can be greater than OA induced by either MIA or STZ. Rats were either injected with MIA (model 1) or STZ (model 2) or both agents (model 3). After 8 weeks, harvested tissues from the knee joint of these groups were examined using scanning and transmission electron microscopy. In addition, blood samples were assayed for tumor necrosis factor alpha (TNF- $\alpha$ ) and interleukin -6 (IL-6) that are known to be modulated in OA and diabetes. Compared to control group, substantial damages to the articular cartilage of the knee joint were observed in the three models with the severest in model 3. In addition, rats in model 3 showed significant $(\mathrm{P}<0.0001)$ increase in TNF- $\alpha$ and IL-6 compared to model 1 and 2. Thus, we have developed a new model of knee OA in rats that mimics a type of OA that is common among elderly people who have both, "ageing" joints and diabetes.

KEY WORDS: Knee osteoarthritis; Diabetes; Monoiodoacetate; Rat model; Cartilage ultrastructure.

\section{INTRODUCTION}

Osteoarthritis $(\mathrm{OA})$ is the most common type of articular disease of the developed world and a leading cause of chronic physical activity and disability, mostly as a consequence of the knee and hip OA (Grazio \& Balen, 2009). Diabetes mellitus (DM) and other conditions linked to it, such as obesity and dyslipidemia have been associated with cardiovascular complications and OA (Haidara et al., 2006; Marshall et al., 2013). Hyperglycemia may have an indirect effect on the cartilage homeostasis by mechanisms involving advanced glycation end-products (AGEs) (Piva et al., 2015). AGEs which accumulate in OA cartilage via activation of their specific receptor, RAGE, play a proinflammatory and pro-catabolic role on chondrocytes and synovial cells and compromise collagen synthesis (Moussa, 2008). High glucose also activates nuclear factor Kappa-B
(NF-K- $\beta$ ) and consequently increased reactive oxygen species production (Rosa et al., 2009). It was also reported that chronic low-grade inflammation, adipokines, inflammatory mediators, such as TNF- $\alpha$ and IL-6 play a role in development of $\mathrm{OA}$ associated with diabetes (Berenbaum, 2012).

Free radicals play a crucial role as a trigger for OA, they directly degrade cartilage components (Burkhardt $e t$ al., 1986) initiating a synovial and immune response that stimulated further cartilage damage. The free radical mechanism of arthritis indicates that antioxidants may play a role in the protection against the damage (Sellam \& Berenbaum, 2013). T1DM patients showed a decrease in antioxidants defenses and an increase in biomarkers of

${ }^{1}$ Departments of Anatomy, College of Medicine, King Khalid University, P.O. 641, Abha, 61421, Saudi Arabia.

${ }^{2}$ Physiology, College of Medicine, King Khalid University, P.O. 641, Abha, 61421, Saudi Arabia.

${ }^{3}$ Orthopedics, College of Medicine, King Khalid University, P.O. 641, Abha, 61421, Saudi Arabia.

${ }^{4}$ Medicine, College of Medicine, King Khalid University, P.O. 641, Abha, 61421, Saudi Arabia.

${ }^{5}$ Pathology College of Medicine, King Khalid University, P.O. 641, Abha, 61421, Saudi Arabia.

${ }^{6}$ Clinical Biochemistry, College of Medicine, King Khalid University, P.O. 641, Abha, 61421, Saudi Arabia.

${ }^{7}$ Departments of Anatomy Kasr Al-Aini Faculty of Medicine, Cairo University, Cairo, Egypt.

${ }^{8}$ Physiology, Kasr Al-Aini Faculty of Medicine, Cairo University, Cairo, Egypt.

* Equally contributed. 
oxidative damage (Kasznicki et al., 2012). In addition, proinflammatory biomarkers IL-6 and TNF- $\alpha$ are significant predictors of knee OA (Livshits et al., 2009; Kou \& Wu, 2014) and OA cartilages from DM patients showed increased responsiveness to IL- $1 \beta$-induced inflammation via oxidative stress and polyol pathway thus participate in the increased inflammation in OA (Laiguillon et al., 2015). On the other hand, chondroprotective agents such as the antioxidants have been found to promote cartilage repair by stimulating anabolic metabolism of chondrocytes and/or inhibiting catabolic processes found in OA (Altman et al., 1987; Bhattacharya et al., 2012). The aim of this work is to develop an animal model of OA induced by a combination of MIA and DM, and investigate the extent of damages to the articular cartilage of the knee joint in this model using scanning and transmission electron microscopy.

\section{MATERIAL AND METHOD}

Animals. The experiments were performed on 24 male Sprague Dawley rats of 10-15 weeks old and weighting (200$250 \mathrm{~g}$ ). The rats were fed with standard laboratory diets, given water ad libitum and maintained under laboratory conditions of temperature $\left(22 \pm 3{ }^{\circ} \mathrm{C}\right)$, with $12 \mathrm{~h}$ light and $12 \mathrm{~h}$ dark cycle. DM was induced using a single injection of STZ, intraperitoneal (i.p.), $65 \mathrm{mg} / \mathrm{kg} \mathrm{BW}$. The diabetes induction was confirmed by measuring blood glucose level 3 days after STZ injection, animals with fasting blood glucose levels greater than $300 \mathrm{mg} / \mathrm{dl}$ were considered diabetic and then included in this study (Haidara et al., 2015). OA was induced chemically by injection of $2 \mathrm{mg}$ of MIA, total volume of $50 \mu \mathrm{L}$, intraarticular, through the patellar ligament of the right knee, using 26-gauge needle, while rat is under anesthesia (sodium thiopentone, $40 \mathrm{mg} \mathrm{kg}^{-1}$, i.p.). Left knee joint was injected with saline as a control (Bar-Yehuda et al., 2009). All of the animals received humane care in compliance with the Public Health Service Policy on Human Care and Use of Laboratory Animals, and were approved by the Ethical Committee of the College of Medicine, King Khalid University.

Experimental design. The animals were randomly allocated into 4 groups $(\mathrm{n}=6)$ as follows: Control group (Control); model group 1, rats were injected with monoiodoacetate (MIA); model group 2, rats were injected with streptozotocin (STZ); and model group 3, rats were injected with both MIA and STZ (MIA + STZ).

Serum sampling. At the end of the $8^{\text {th }}$ week of the experiment, $5 \mathrm{ml}$ retro-orbital blood samples were obtained under anesthesia using $40 \mathrm{mg} / \mathrm{Kg}$ sodium thiopentone, i.p. After an overnight fast, $3 \mathrm{~mL}$ were collected into $3.8 \%$ sodium citrate anticoagulant for plasma separation. While $2 \mathrm{ml}$ were collected into plain tubes, then allowed to clot for 20 min then centrifuged at $14000 \mathrm{rpm}$ for $10 \mathrm{~min}$ for serum separation. Then plasma and serum were stored at $-80^{\circ} \mathrm{C}$, for subsequent measurements of biochemical parameters.

Biochemical parameters. Rat ELISA kits were used for measurements of TNF- $\alpha$, (TSZ ELISA, Framingham, MA, USA), and IL-6, (Ray Biotech Inc., Norcross, GA, USA).

Specimen preparation for electron microscopic examination. After withdrawal of the blood sample animals were killed by decapitation while under anesthesia, then the knee joints were opened, dissected and fixed and kept for electron-microscopic examination. Samples were assigned a second random number, thus to keep the study blinding.

Scanning electron microscopy (SEM). Small pieces of cartilage were removed from the deep zone of different location of the AC . The deep zone was the largest zone, occupying $60-80 \%$ of the uncalcified cartilage. Multiple random samples taken from each piece of cartilage were fixed with $2.5 \%$ (wt/ vol) sodium cacodyl buffered glutaraldehyde, $\mathrm{pH} 7.2$ at $4{ }^{\circ} \mathrm{C}$ for $2 \mathrm{~h}$. Samples were also post-fixed in $1 \%$ sodium cacodyl buffered osmium tetroxide, $\mathrm{pH} 7.2$ for $1 \mathrm{~h}$. Samples were then washed and dehydrated in ascending grades of ethanol, critical point drying was performed using the EMITECH-K850critical point drying unit. The samples were mounted on aluminum stubs with double sided tape and silver glue and then sputter coated with gold by Boc Edwards Scan coat (Eid et al., 2012). The specimens were observed using a Jeol scanning electron microscope JSM-6390LV, Japan.

Transmission electron microscopy (TEM). Small pieces of cartilage were removed from the deep zone of different location of the AC. Multiple random samples were taken from each piece of cartilage were processed into $2.5 \%$ glutaraldehyde for 24 hours, the small pieces then washed by phosphate buffer (0.1 M, PH 7.4). Post fixation was made in $1 \%$ osmium tetroxide buffered to PH 7.4 with $0.1 \mathrm{M}$ phosphate buffer at 4 ${ }^{\circ} \mathrm{C}$ for 1-2 hours, washed again in phosphate buffer to remove excess fixative. Samples were then washed and dehydrated through ascending grades of ethanol followed by clearing in propylene oxide. The specimens were embedded in araldite 502, to form gelatin capsules. Polymerization was obtained by placing the capsules at $60^{\circ} \mathrm{C}$. Semi-thin sections about one $\mathrm{mm}$ thickness, stained with toluidine blue were made for orientation and observation. Ultra-thin sections $(100 \mathrm{~nm})$ were prepared using ultra-microtome and picked up on uncoated copper grids. Following double staining with uranyl acetate and lead citrate, sections were examined and photographed using $1200 \mathrm{EX}$ - JEOL transmission electron microscope, Japan, at $80 \mathrm{Kv}$ (Hayat, 1989). 
Statistical analysis. Values are measured as mean \pm SD. Comparison of data was performed by using One-way ANOVA test (analysis of variance test) using graph pad prism analysis software, version 5. Probability $(\mathrm{P})$ values of $<0.05$ were considered to be significant.
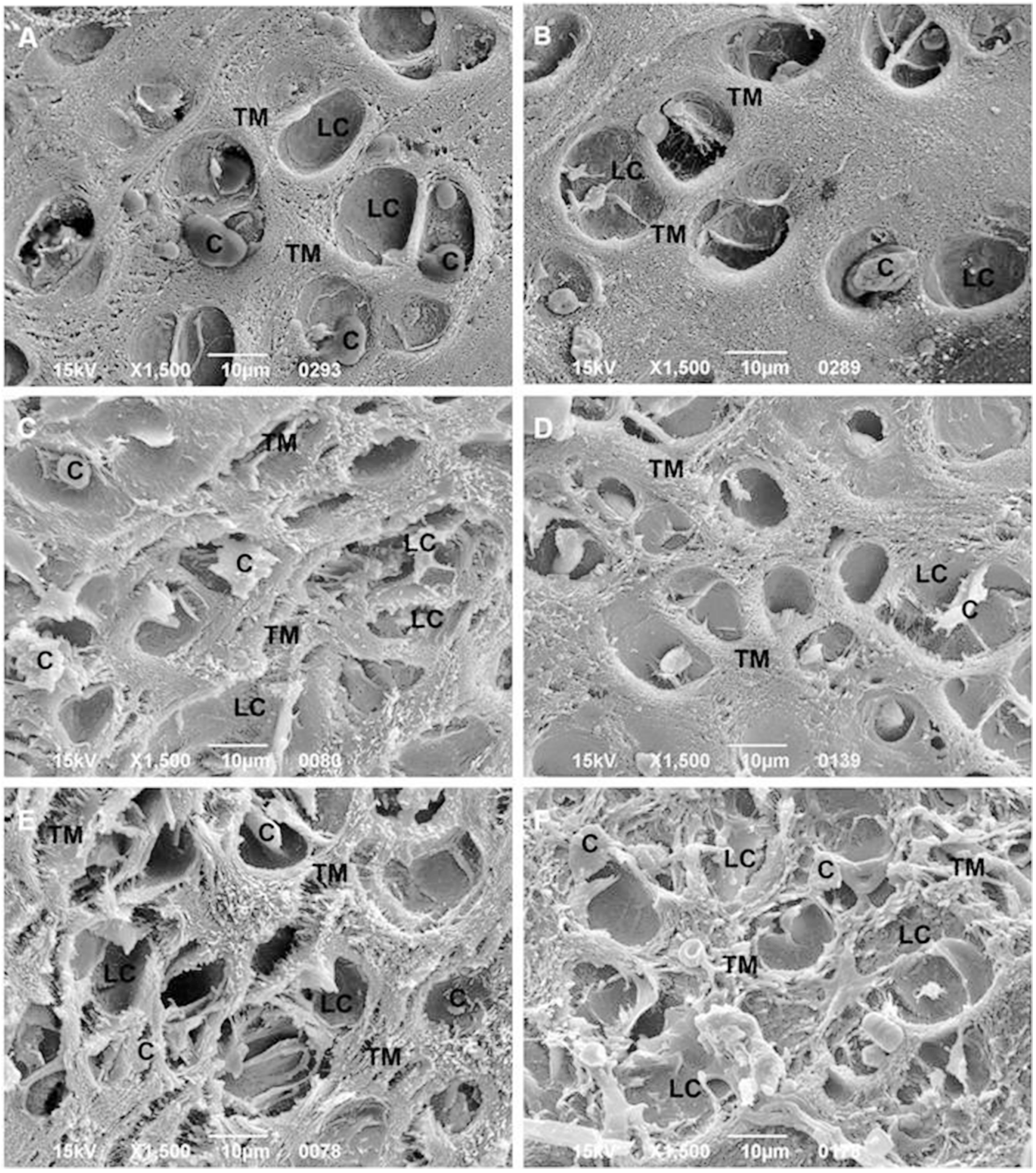

Fig. 1. OA induced in rats by MIA+STZ caused severe damages to the articular cartilage. SEM images (x 1500) of tissues obtained from the articular cartilage 8 weeks post OA and diabetic induction. (A and B) Control group. (C) Model group 1, rats were injected with MIA. (D) Model group 2, rats were injected with STZ. (E and F) Model group 3, rats were injected with MIA and STZ. Abbreviations: C, chondrocyte; LC, leaving lacunae; TM, territorial matrix. 


\section{RESULTS}

Development of an animal model of knee OA induced by MIA and STZ. Sprague Dawley rats were injected with a single dose of citrate buffer as a control group, MIA $(2 \mathrm{mg} /$
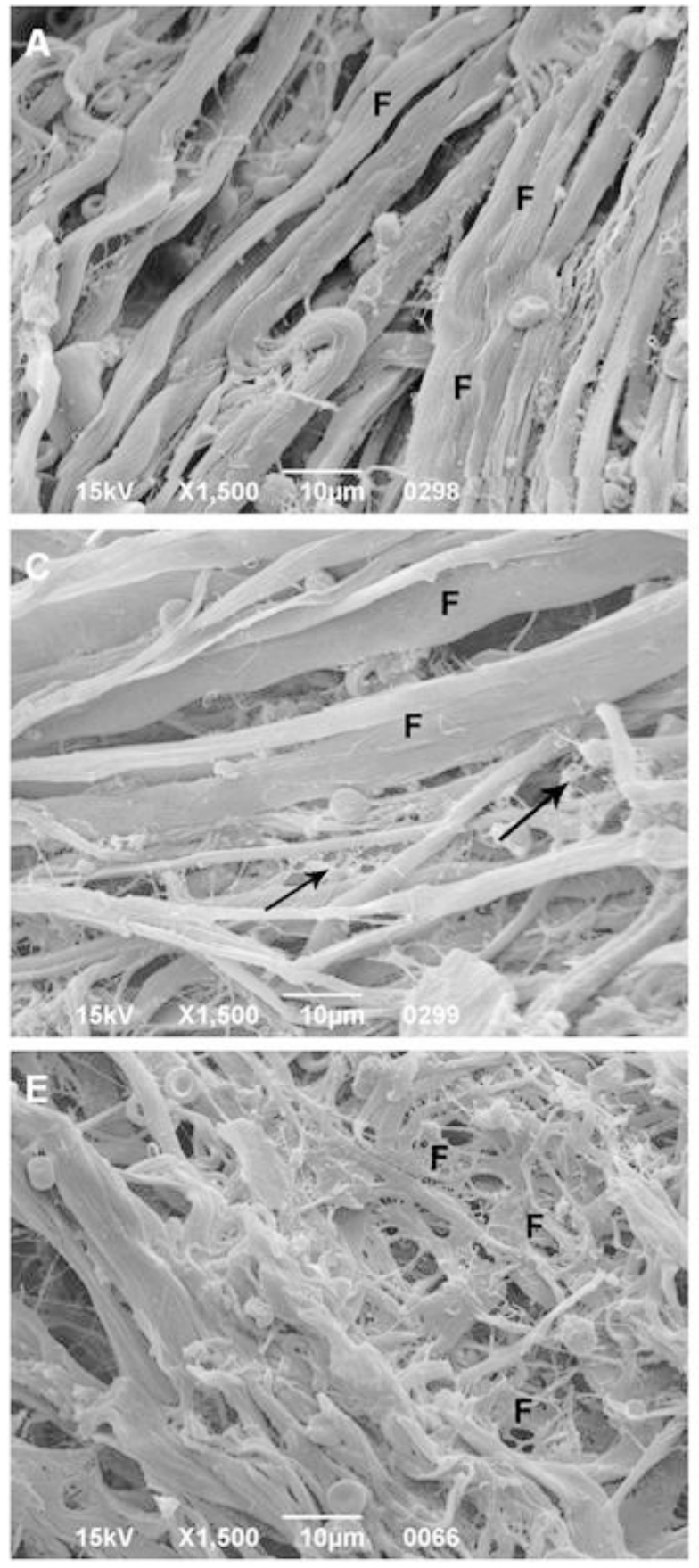

$50 \mu \mathrm{l})$ for model group 1(Bar-Yehuda et al.), STZ (65 mg/ $\mathrm{kg}$ ) for model group 2 (Haidara et al., 2004), and both MIA and STZ for model group 3. All rats received STZ (model groups 2 and 3) showed hyperglycaemic blood levels that exceeded $300 \mathrm{mg} / \mathrm{dl}$ three days post STZ injections compared to a normal blood sugar in the control group (data not shown).
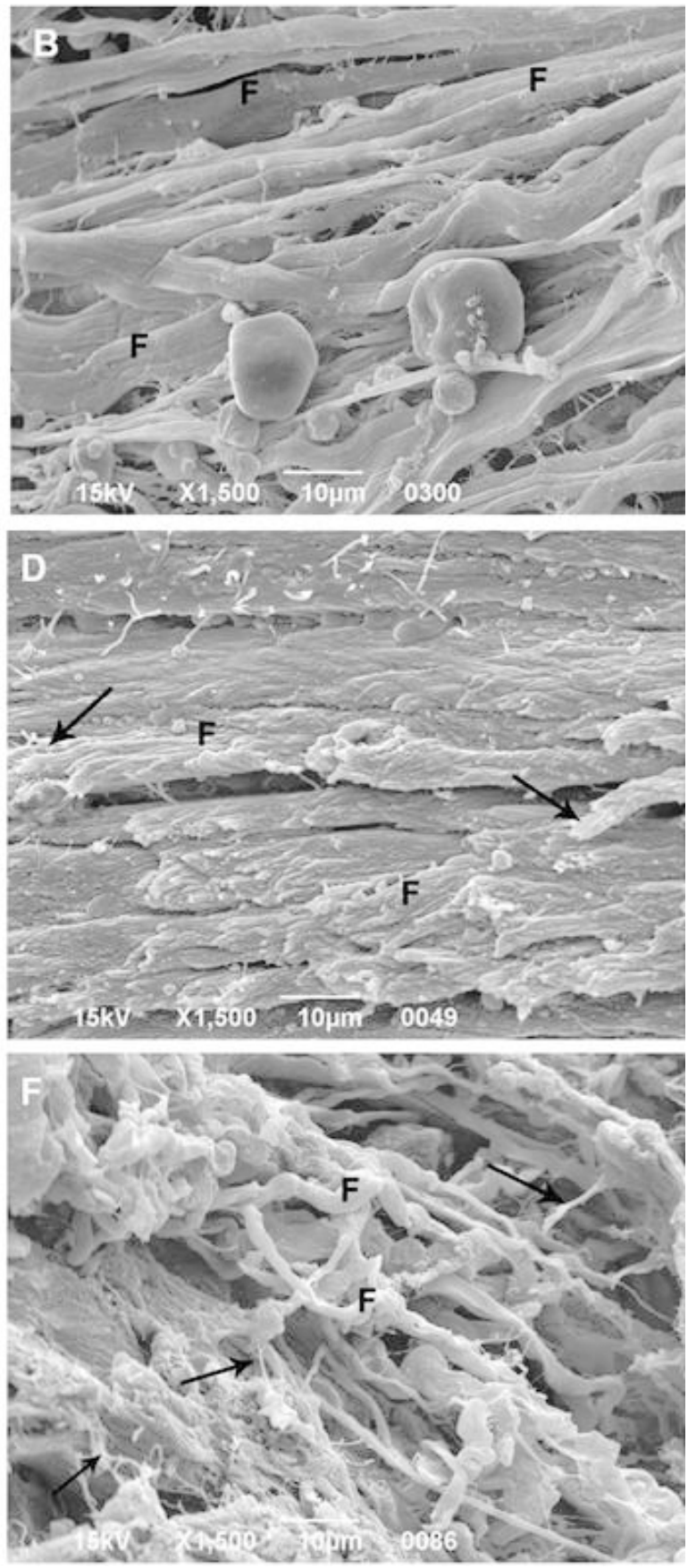

Fig. 2. OA induced in rats by MIA+STZ caused severe damages to the collagen fibers. SEM images (x 1500) of collagen fibers tissues obtained from the articular cartilage 8 weeks post OA and diabetic induction. (A and B) Control group. (C) Model group 1, rats were injected with MIA. (D) Model group 2, rats were injected with STZ. (E and F) Model group 3, rats were injected with MIA and STZ. Note that arrows point to focal damage of collagen fibril sheets. Abbreviations: F, normal collagen fibril sheets (A and B) and abnormal collagen fibril sheets in C and D. 

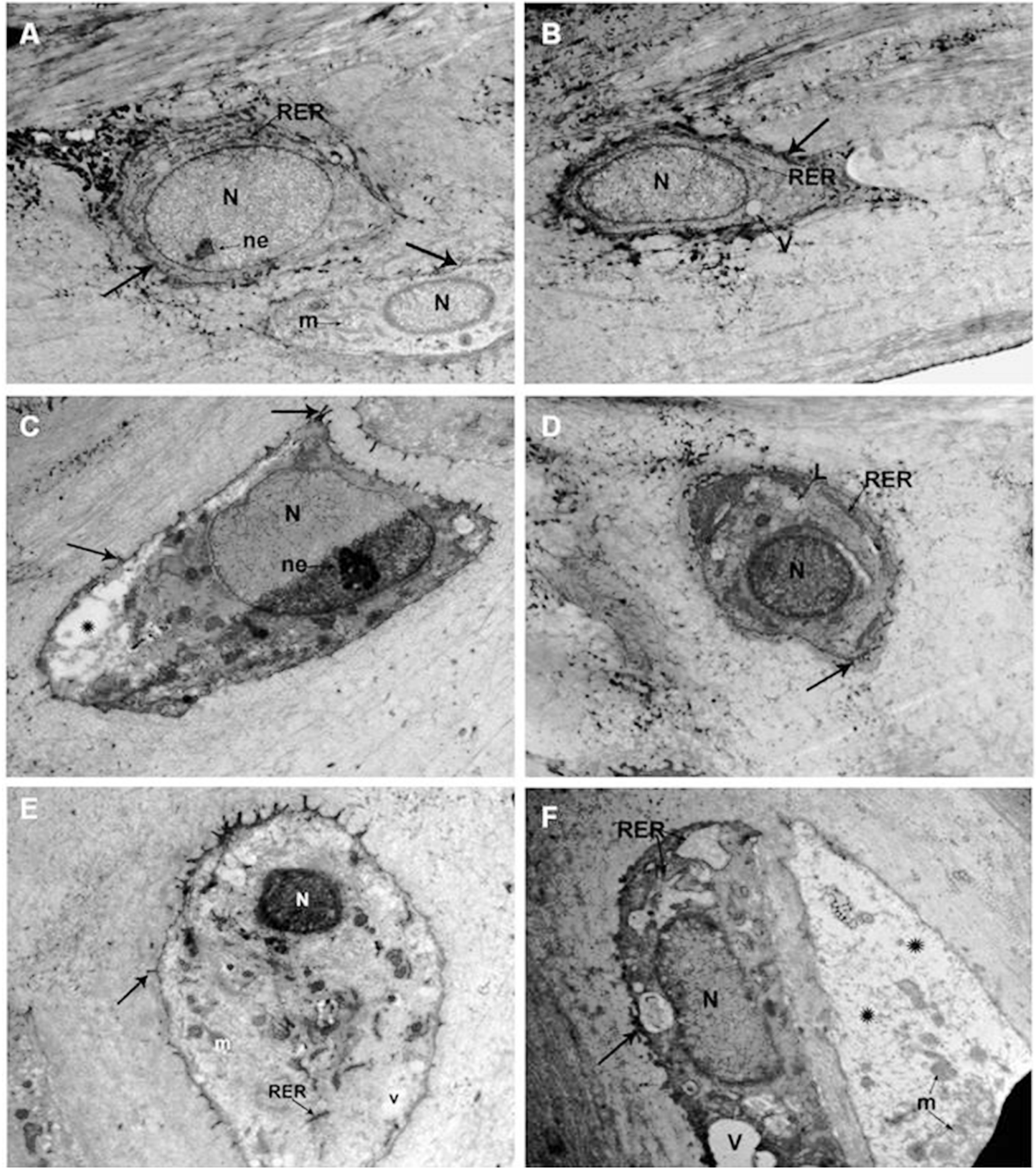

Fig. 3. OA induced in rats by MIA+STZ caused severe damages to the articular cartilage ultrastructure. TEM images (x 8000) of tissues obtained from the articular cartilage 8 weeks post OA and diabetic induction. (A and B) Control group. (C) Model group 1, rats were injected with MIA. (D) Model group 2, rats were injected with STZ. (E and F) Model group 3, rats were injected with MIA and STZ. Note that thick arrows point to the short cell process and stars point to damaged cytoplasm. Abbreviations: N, nucleus; ne, nucleolus; RER, rough endoplasmic reticulum; m, mitochondria; V, vacuoles; L, lipid droplet. 
Tissue preparations for SEM (Figs. 1 and 2) and TEM (Fig. 3) analyses from the articular cartilage of the knee joint of the sacrificed rats revealed $\mathrm{OA}$ development after 8 weeks in the three model groups (Figs. $1 \mathrm{C}-1 \mathrm{~F} ; 2 \mathrm{C}-2 \mathrm{~F}$; and $3 \mathrm{C}-$ $3 \mathrm{~F})$ compared to a normal cartilage architecture and ultrastructure components in the control group (Figs. 1A and $1 \mathrm{~B}, 2 \mathrm{~A}$ and $2 \mathrm{~B}$, and $3 \mathrm{~A}$ and $3 \mathrm{~B}$ ). There was a differential in the intensity of tissue damages with the severest deterioration was observed in the knee joint of model group 3 as shown by a total destruction of the articular cartilage structures such as atrophic chondrocytes, distorted lacunae, damaged territorial matrix and collagen fibres (Figs. $1 \mathrm{E}$ and $1 \mathrm{~F}$; and $2 \mathrm{E}$ and $2 \mathrm{~F}$ ). In addition, TEM images in the animal group that

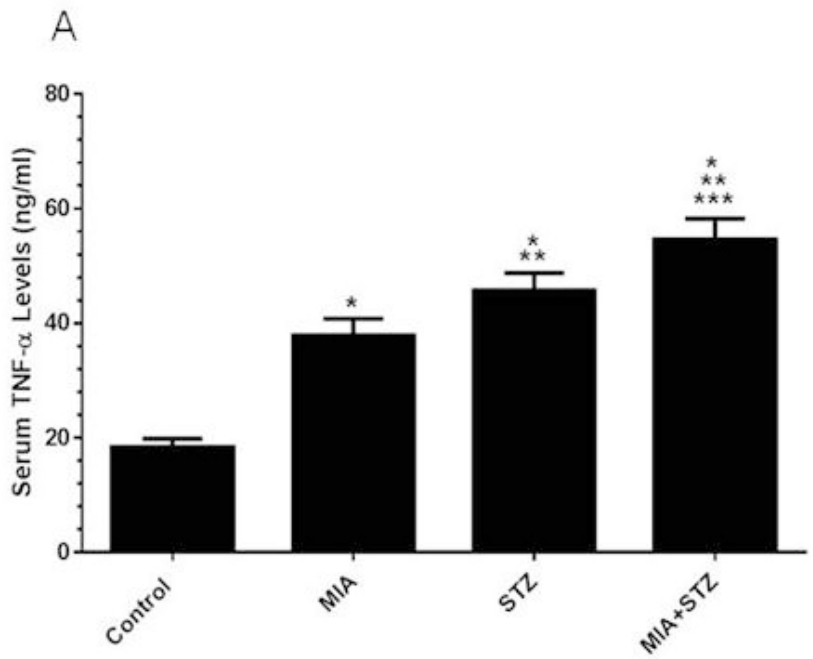

received MIA plus STZ showed vacuoles in the cytoplasm and damaged mitochondria, nucleus, and rough endoplasmic reticulum (RER) (Figs. 3E and 3F).

Induction of TNF- $\alpha$ and IL- 6 by MIA and STZ. The proinflammatory cytokines, TNF- $\alpha$ and IL- 6 are known to be involved in the pathology of diabetes and OA. We measured the blood level of these cytokines 8 weeks after induction of diabetes and OA (Fig. 4). Compared to control, TNF- $\alpha$ and IL- 6 blood levels were increased by three-fold and eight-fold, respectively. The relative increase in TNF- $\alpha$ and IL-6 levels among the three model groups were model group $3>$ model group $2>$ model group 1 .

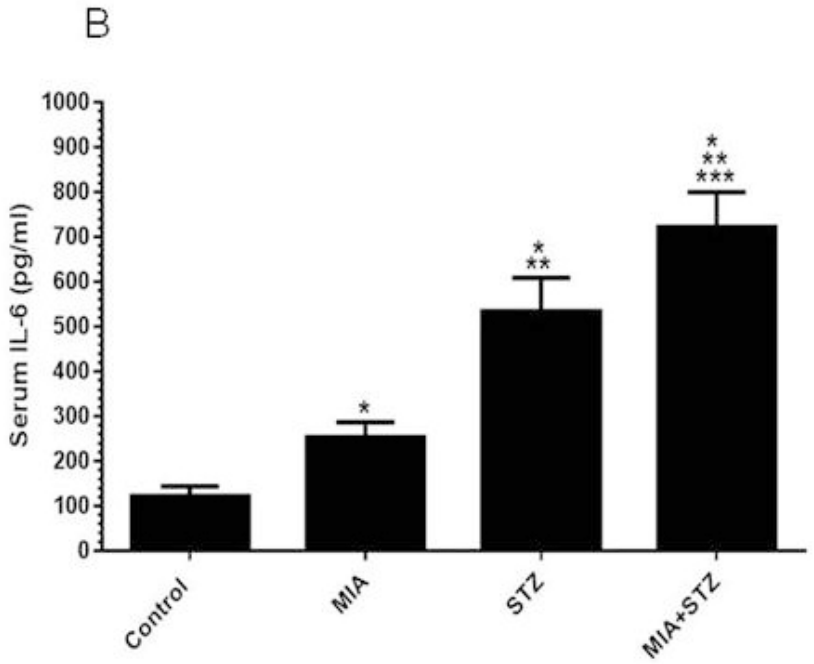

Fig. 4. MIA and STZ induced TNF- $\alpha$ and IL-6 release . Blood levels of TNF- $\alpha$ (A) and IL-6 (B) were measured 8 weeks post OA and diabetes induction by MIA and STZ in 4 groups of rats; control, MIA, STZ, and MIA+STZ . Results represent the mean ( \pm SD); $n=6$ for each group. Experiments were performed in triplicate. In $\mathrm{A}$, $* \mathrm{P}<0.0001$ versus control; $* * \mathrm{P}<0.0001$ versus $\mathrm{MIA}$; and $* * * \mathrm{P}=0.0005$ versus STZ. Whereas, in $\mathrm{B}, * \mathrm{P}<0.01$ versus control; ** $\mathrm{P}<0.0001$ versus MIA; and $* * * \mathrm{P}=0.0002$ versus $\mathrm{STZ}$.

\section{DISCUSSION}

The main objectives of our study were to develop an animal model of knee OA that mimics the disease in humans caused by the 'wear and tear' of the knee joints combined with the advanced type of diabetes since OA is a known complication of diabetes (Schett et al., 2013). We also wished to compare the pathological effects induced by this model with the known OA animal models induced by one causative agent only. Therefore, rats' knee joints were injected directly with MIA to mimic the 'wear and tear' scenario and intraperitoneally with STZ to induce diabetes and compare it with other groups of rats that received either MIA or STZ. The principal findings in our study were that MIA+STZ induced knee OA, which presented the severest damages compared to others, and also induced the highest blood levels of the measured inflammatory biomarkers. These conclusions are supported by SEM, TEM, and ELISA studies (Figs. 1-4) indicating that MIA plus STZ caused severe destruction of the articular cartilage (Figs 1-3) and upregulation of TNF-? and IL-6 (Fig. 4) that are known to be modulated by OA and diabetes (Korczowska \& Lacki, 2005, Livshits et al.). It was of particular interest to us that the relative pathological tissue destruction induced by this model (model group 3 ) compared to others (model groups 1 and 2) (Figs. 1-3) mirrored the activities of the inflammatory biomarkers in the blood of these animals (Fig. 4) that also showed the highest levels in model group 3. Our results were thus consistent with our working hypothesis that the production of a knee OA animal model via combining MIA and STZ can be more destructive than OA induced by either MIA or STZ. 
Prolonged hyperglycemia and increased advanced glycation end products (AGEs) were proposed to contribute to OA development (Yan \& Li, 2013). Our recent work on the induction of diabetes in an animal model induced knee $\mathrm{OA}$ and insulin was found to protect against knee OA in diabetes-induced OA in rats (El Karib et al., 2016) and the increase in proteoglycan and matrix synthesis in articular cartilage explants obtained from diabetic mice (Cai et al., 2002) supported the well known role of diabetes-induced $\mathrm{OA}$ in human. In addition, MIA is used to induced OA in animal models (Combe et al., 2004; Stevenson et al., 2011). Therefore, our approach to include diabetes as a predisposing factor in knee OA with MIA was justified.

Our data that showed a significant $(\mathrm{p}<0.0001)$ increase in the blood levels of TNF- $\alpha$ and IL- 6 in the animal model point to these inflammatory biomarkers as important non-invasive tool to monitor the disease activity of knee OA. This is in agreement with the previously published work on the role of TNF- $\alpha$ and IL- 6 in the pathogenesis of inflammation induced cartilage destruction (Fuller et al., 2002; Korczowska \& Lacki; Kapoor et al., 2011) and the reports that proposed IL- 6 and TNF- $\alpha$ as significant predictors of knee OA (Livshits et al.; Kou \& $\mathrm{Wu})$.

In conclusion, our data demonstrate that MIA combined with STZ induced a sever type of knee OA in rats, and this animal model can mimic the human knee OA caused by both ageing and diabetes.

Sources of Funding: This work was supported by King Khalid University grant number KKU-Project No 2 (201).

HEIDAR, E. H. A.; AL- ANI, B.; HAIDARA, M. A.; AL FAYA, F. F.; AL HUMAYED, S.; EID, R. A. \& HASSAN, W. N. Desarrollo de un modelo de rata de osteoartritis de rodilla por una combinación de monoiodoacetato y estreptozotocina. Int. J. Morphol., 35(4):1383-1390, 2017.

RESUMEN: La osteoartritis (OA) es un problema generalizado de salud a causa de un envejecimiento de las articulaciones, o bien de una complicación secundaria de la diabetes. El objetivo de este estudio fue desarrollar un modelo animal de OA inducido por una combinación dos drogas, un inhibidor de los condrocitos glucolíticos, el mono-iodoacetato (MIA), y la estreptozotocina (STZ), agente que induce la diabetes mellitus. Se consideró como hipótesis que el alcance de los daños a la articulación de la rodilla inducida por este modelo puede ser mayor que la OA inducida por MIA o STZ. Las ratas fueron inyectadas con MIA (grupo 1) o STZ (grupo 2) o ambos agentes (grupo 3). Se extrajeron muestras de la articulación de la rodilla de estos grupos al término de 8 semanas, y se examinaron mediante microscopía elec- trónica de barrido y de transmisión. Además, se analizaron muestras de sangre para el factor de necrosis tumoral alfa (TNF- $\alpha$ ) e interleucina-6 (IL-6), que están moduladas en OA y en la diabetes. En comparación con el grupo control, se observaron daños sustanciales en el cartílago articular de la articulación de la rodilla en los tres modelos, encontrándose los daños más severos en el grupo 3. Además, las ratas del grupo 3 mostraron un aumento significativo (P <0,0001) de los niveles de TNF- $\alpha$ e IL- 6 , en comparación con los grupos 1 y 2 . Hemos desarrollado un nuevo modelo de OA de rodilla en ratas que imita un tipo de OA el cual, además de la diabetes, es común entre las personas mayores con un nivel importante de daño en las articulaciones.

PALABRAS CLAVE: Osteoartritis de rodilla; Diabetes; Monoisoacetato; Modelo de rata; Ultraestructura del cartílago.

\section{REFERENCES}

Altman, R. D.; Howell, D. S. \& Gottlieb, N. L. New directions in therapy of osteoarthritis. Semin. Arthritis Rheum., 17(2 Suppl. 1):1-2, 1987.

Bar-Yehuda, S.; Rath-Wolfson, L.; Del Valle, L.; Ochaion, A.; Cohen, S.; Patoka, R.; Zozulya, G.; Barer, F.; Atar, E.; Piña-Oviedo, S.; Perez-Liz, G.; Castel, D. \& Fishman, P. Induction of an antiinflammatory effect and prevention of cartilage damage in rat knee osteoarthritis by CF101 treatment. Arthritis Rheum., 60(10):3061-71, 2009.

Berenbaum, F. Diabetes-induced osteoarthritis: from a new paradigm to a new phenotype. Postgrad. Med. J., 88(1038):240-2, 2012.

Bhattacharya, I.; Saxena, R. \& Gupta, V. Efficacy of vitamin E in knee osteoarthritis management of North Indian geriatric population. Ther. Adv. Musculoskelet. Dis., 4(1):11-9, 2012.

Burkhardt, H.; Schwingel, M.; Menninger, H.; Macartney, H. W. \& Tschesche, H. Oxygen radicals as effectors of cartilage destruction. Direct degradative effect on matrix components and indirect action via activation of latent collagenase from polymorphonuclear leukocytes. Arthritis Rheum., 29(3):379-87, 1986.

Cai, L.; Okumu, F. W.; Cleland, J. L.; Beresini, M.; Hogue, D.; Lin, Z. \& Filvaroff, E. H. A slow release formulation of insulin as a treatment for osteoarthritis. Osteoarthritis Cartilage, 10(9):692-706, 2002.

Combe, R.; Bramwell, S. \& Field, M. J. The monosodium iodoacetate model of osteoarthritis: a model of chronic nociceptive pain in rats? Neurosci. Lett., 370(2-3):236-40, 2004.

Eid, R. A.; Radad, K. \& Al-Shraim, M. Ultrastructural changes of smooth muscles in varicocele veins. Ultrastruct. Pathol., 36(4):201-6, 2012.

El Karib, A. O.; Al-Ani, B.; Al-Hashem, F.; Dallak, M.; Bin-Jaliah, I.; ElGamal, B.; Bashir, S. O.; Eid, R. A. \& Haidara, M. A. Insulin and vanadium protect against osteoarthritis development secondary to diabetes mellitus in rats. Arch. Physiol. Biochem., 122(3):148-54, 2016.

Fuller, K.; Murphy, C.; Kirstein, B.; Fox, S. W. \& Chambers, T. J. TNFalpha potently activates osteoclasts, through a direct action independent of and strongly synergistic with RANKL. Endocrinology, 143(3):1108$18,2002$.

Grazio, S. \& Balen, D. Obesity: risk factor and predictor of osteoarthritis. Lijec. Vjesn., 131(1-2):22-6, 2009.

Haidara, M. A.; Assiri, A. S.; Youssef, M. A.; Mahmoud, M. M.; Eajaz, A.; Al-Hakami, A. \& Chandramoorthy, H. C. Differentiated mesenchymal stem cells ameliorate cardiovascular complications in diabetic rats. Cell Tissue Res., 359(2):565-75, 2015.

Haidara, M. A.; Khloussy, H.; Ammar, H. \& Aal Kassem, L. A. Impact of alpha-tocopherol and vitamin $\mathrm{C}$ on endothelial markers in rats with streptozotocin-induced diabetes. Med. Sci. Monit., 10(2):BR41-6, 2004. 
HEIDAR, E. H. A.; AL- ANI, B.; HAIDARA, M. A.; AL FAYA, F. F.; AL HUMAYED, S.; EID, R. A. \& HASSAN, W. N. Development of a rat model of knee osteoarthritis by a combination of monoiodoacetate and streptozotocin. Int. J. Morphol., 35(4):1383-1390, 2017.

Haidara, M. A.; Yassin, H. Z.; Rateb, M.; Ammar, H. \& Zorkani, M. A. Role of oxidative stress in development of cardiovascular complications in diabetes mellitus. Curr. Vasc. Pharmacol., 4(3):215-27, 2006.

Hayat, M. A. Principles and Techniques of Electron Microscopy Biological Application. $3^{\text {rd }}$ Ed. Boca Raton, CRC Press, 1989. pp.469-75.

Kapoor, M.; Martel-Pelletier, J.; Lajeunesse, D.; Pelletier, J. P. \& Fahmi, H. Role of proinflammatory cytokines in the pathophysiology of osteoarthritis. Nat. Rev. Rheumatol., 7(1):33-42, 2011.

Kasznicki, J.; Kosmalski, M.; Sliwinska, A.; Mrowicka, M.; Stanczyk, M.; Majsterek, I. \& Drzewoski, J. Evaluation of oxidative stress markers in pathogenesis of diabetic neuropathy. Mol. Biol. Rep., 39(9):8669-78, 2012.

Korczowska, I. \& Lacki, J. K. Changes in certain biochemical markers of bone turnover in rheumatoid arthritis patients treated with short-term low dose glucocorticosteroids. Przegl. Lek., 62(12):1384-6, 2005.

Kou, S. \& Wu, Y. Meta-analysis of tumor necrosis factor alpha -308 polymorphism and knee osteoarthritis risk. B. M. C. Musculoskelet. Disord., 15:373, 2014

Laiguillon, M. C.; Courties, A.; Houard, X.; Auclair, M.; Sautet, A.; Capeau, J.; Fève, B.; Berenbaum, F. \& Sellam, J. Characterization of diabetic osteoarthritic cartilage and role of high glucose environment on chondrocyte activation: toward pathophysiological delineation of diabetes mellitus-related osteoarthritis. Osteoarthritis Cartilage, 23(9):1513-22, 2015.

Livshits, G.; Zhai, G.; Hart, D. J.; Kato, B. S.; Wang, H.; Williams, F. M. \& Spector, T. D. Interleukin-6 is a significant predictor of radiographic knee osteoarthritis: The Chingford Study. Arthritis Rheum., 60(7):203745, 2009.

Marshall, M.; Peat, G.; Nicholls, E.; van der Windt, D.; Myers, H. \& Dziedzic, K. Subsets of symptomatic hand osteoarthritis in communitydwelling older adults in the United Kingdom: prevalence, interrelationships, risk factor profiles and clinical characteristics at baseline and 3-years. Osteoarthritis Cartilage, 21(11):1674-84, 2013.

Moussa, S. A. Oxidative stress in diabetes mellitus. Rom. J. Biophys., 18(3):225-36, 2008

Piva, S. R.; Susko, A. M.; Khoja, S. S.; Josbeno, D. A.; Fitzgerald, G. K. \& Toledo, F. G. Links between osteoarthritis and diabetes: implications for management from a physical activity perspective. Clin. Geriatr. Med., 31(1):67-87, 2015.

Rosa, S. C.; Gonçalves, J.; Judas, F.; Mobasheri, A.; Lopes, C. \& Mendes, A. F. Impaired glucose transporter-1 degradation and increased glucose transport and oxidative stress in response to high glucose in chondrocytes from osteoarthritic versus normal human cartilage. Arthritis Res. Ther. 11(3):R80, 2009.

Schett, G.; Kleyer, A.; Perricone, C.; Sahinbegovic, E.; Iagnocco, A.; Zwerina, J.; Lorenzini, R.; Aschenbrenner, F.; Berenbaum, F.; D'agostino, M. A.; Willeit, J. \& Kiechl, S. Diabetes is an independent predictor for severe osteoarthritis: results from a longitudinal cohort study. Diabetes Care, 36(2):403-9, 2013.

Sellam, J. \& Berenbaum, F. Is osteoarthritis a metabolic disease? Joint Bone Spine, 80(6):568-73, 2013.

Stevenson, G. W.; Mercer, H.; Cormier, J.; Dunbar, C.; Benoit, L.; Adams, C.; Jezierski, J.; Luginbuhl, A. \& Bilsky, E. J. Monosodium iodoacetateinduced osteoarthritis produces pain-depressed wheel running in rats: implications for preclinical behavioral assessment of chronic pain. Pharmacol. Biochem. Behav., 98(1):35-42, 2011.

Yan, W. \& Li, X. Impact of diabetes and its treatments on skeletal diseases. Front. Med., 7(1):81-90, 2013.

\author{
Corresponding author: \\ Professor Mohamed A Haidara \\ Department of Physiology \\ College of Medicine \\ King Khalid University \\ Abha 61421 \\ SAUDI ARABIA
}

E-mail: haidaram@hotmail.com

Received: 10-04-2017

Accepted: 05-06-2017 